tremely rare symptom in typhus fever; and that the intestinal. bemorrhage, which is so common a feature of enteric fever, is rarely, if ever, accompanied by hæmatemesis. Intestinal homorrhage is, indeed, almost a pathognomonic symptom of enteric fever; but the blood in such cases is always, I believe, from the ulcerated patches of Peyer, low down in the ileum, and accordingly blood is never voided upwards, except by a mere accidental coincidence. In this case of ours, accordingly, there need be no doubt that the blood is from the upper part of the canal, and not from Peyer's patches. The disease is typhns, the eruption is typhus, and we have some rare complication pro. bably in the stomach; it may be a gastric ulcer, only we have absolutely no antecedent history of a gastric ulcer. Perhaps it is in vain to speculate as to the precise character of the lesion, as we have no experience to guide us. I have looked into Dr. Murchison's book. lattly published, which is by far the most accurate and complete repository of the facts on record as to the fevers of this country, and I find not a word about brematemesis in typhus, though a form of "black vomit" (so-called) was an occasional symptom in the relapsing fever of 1843, and Chomel mentions one case in which blood was vomited in enteric fever My own recollections, as I toll you, furnish no case similar to the present one, and on these grounds I am inclined to believe that the hremorrhage is merely an accidental coincidence. It is important to observe that the loss of blood in this case has scarcely interfered at all with the natural progress of the fever. It has, of course, seriously weakened the patient, but it has not increased the delirium or delayed the crisis. I am not quite certain that it may not have had an opposite effect; and there are not wanting authorities who believe that in fevers the crisis is sometimes determined by hæmorrhage, though I do not participate in their opinion that bæmorrhage in fever is usually, or other than very rarely, of favourable import as respects the prognosis. In this young girl, I am glad to say, there is at least no appearance as yet of any pernanent bad effect from this enormous loss of blood. She is pale and weak, but is decidedly improving in strength, and she has no pain or other evidence of local disease. [Her convalescence was uninterrupted.]

Another case of considerable interest is one of typhus fever complicated with partial paralysis of the left portio dura.

[This patient was, at the time of the lecture, in imperfect convalescence after a severe attack of fever, and no information could be obtained as to his antecedents. I therefore remarked at considerable length on the rarity of hemiplegic paralysis in typhus fever, notwithstanding the frequency of delirium and other functional affections of the brain. The paralysis of the mouth and eyelid in connexion with the cerebral symptoms proper to typhus, might reasonably have suggested some grave structural disease of the brain, but for the knowledge that such forms of disease are very rare in typhus. Besides, paralysis of the mouth and eyelid, unaccompanied by hemiplegic paralysis of the body, is very likely to be due to a local lesion of the trunk of the portio dura; and this was accordingly the view I expressed as to the probabilities in the case referred to. On the patient's more complete recovery, he told us that long before the fever there had been a "twist" in his month. "The convalescence was in all respects as usual, though rather slow. The treatment adopted in view of the paralysis was a blister behind the ear.

It is worth while to conclude this report by a brief allusion to a few other incidents of the winter session, bearing on the subject of fever. In one case of typhus, nearly at the time of the acme, squinting occurred to a marked extent, and for twentyfour hours. This is, according to my experience, so very rare a complication of typhus, that it attracted particular attention at the time, and although it passed away with the convales cence, $I$ find it difficult even now to divest myself of the in pression that it arose from some unseen complication about the base of the brain. In one case, in the midst of an imperfect crisis, emphysema of the cellular tissue of the right arm and neek occurred on the nineteenth day of the fever, followed by fatal collapse. After death air was found in the cellular tissue at the root of the right lung, and around the pericardium there was a streak of interlobular emphysema at the anterior part of the lower lobe, but no vesicular emphysema. The mucous membrane of the air-passages was apparently uninjured, but in either lung was a single small nodule, of recent condensation, obviously breaking down into suppuration, and in the right lung into gangrene, with a mawkishly fetid odour. It sef $m$ s probable that the emphysematous lesion had something to do with this lesion, though the exact channel of communication of the air could not be traced.

There. were two abortions in typhus fever, one at the second, the otber at the third month, attended with considerable hemorrhage. It is remarkable that both patients made good recoveries, and that one other pregnant woman carried the foetus uninjured through the fever, though making but a slow convalescence. In one of the abortions the hæmorrhage was supposed by the nurse to be from the bowels, which led to a puzzle for a time, as the case was undoubtedly one of typhus. The patient was unmarried, and had not declared herself preg. nant. I have seen menstrual hæemorrbage occurring during fever, in like manner, supposed to be from the bowels. W. T. G.]

\section{DR. H. SNELLEN'S TEST-TYPES}

\section{FOR ASCERTAINING THE ACUTENESS (DEFINITION) OF} SIGAT.

By CHAPLES BADER, EsR,

OPfTHALMTC ASBISTANT-SURGEOY TO GUY'S HOSPITAL.

I BEG to call the attention of the profession to the test-typess of Dr. H. Snellen (assistant to Prof. Donders, University of Utrecht, Holland). These types furnish us with means supe. rior to those which have hitherto been in use for ascertaining the acuteness of sight. Although the latter may be impaired by various causes, we find it necessary to determine exactly the degree of impairment preliminary to the investigation of other morbid changes. To the patient defective sight, whatever the cause may be, is not a symptom, but practically a disease. It is also of importance to us to possess means for ascertaining the degree of acuteness of sight of healthy eyes of different ages as a standard for comparison with impaired eyes; for instance, if a patient, who is only able to distinguish at two feet distance what a normal eye - say of the same age-can dis. cern at a distance of seven feet, we should pronounce the acnte. ness of sight (the defining power) of the patient's eye equal to. two-sevenths of the normal one.

The plan hitherto adopted has been to use letters or words of different sizes, for which, however, the distance at which a normal eye should be able to distinguish them was not aseertained. The best known tests of this kind are those of Prof Jaeger, of Vienna. The test chosen ought to be in all its parts homogeneous, or of the same degree of severity. If one single letter in a word, or even only a single stroke of one letter, were less distinguishable than the rest, that part wonld evidently correspond to a test of a higher degree of severity. $\mathbf{A n}$ exact judgment as to the state of sight is prevented by such a mixture of different tests, which is also apt to deceive the patient. It was, therefore, necessary to construct letters every single part of which would afford the same test, so that a patient who can make ont one single letter or word should be able to distinguish as clearly every other of the same degree at the same distance. This desideratum is most ingeniously ful filed by Dr. Snellen's test-types.

Tables 1 to 4 contain series of test-letters, preference having been given to initials, in order to obtain perfectly square forms -i. e., of equal height and breadth, the strokes of which (ascending, descending, horizontal, and perpendicular) are of exactly the same thickness or calibre (equal to one-fifth of the total height or breadth of the letter), the intervals between the letters being also square. It was necessary to construct such letters with the greatest care on the lithographic stone, as the ablest draughtsman, provided only with the usual implements of rule, compass, and drawing-pen, would never arrive at a sufficient degree of accuracy.

Tables 5 to 8 give reading specimens, for which that sort of type which seemed the nearest approach to the form of the above-mentioned test-letters has been selected.

Tables 9 and 10 contain systems of horizontal and vertical lines, and also chequered (chessboard-like) figures, which may be used for recognising bigher degrees of astigmatism. It would, perhaps, have been well to have a still greater variety of tests of this description, since systems of lines of varions degrees of fineness seem to afford the most perfect (the best numerically comparable) test for our purpose.

Table 11 exhibits coloured letters on a black background, for deternining the state of sight relative to perception of colour (colonr-blindness, \&c.)

Tables 12 and 13, tinally, contain some more letters of the first-mentioned description, but on larger scales, Table 12 show- 
ing the same letters black on a white ground, while Table 13 exhibits white on a black ground. This diversification allows us further to develop our diagnosis in the way described in the short and well-written preface, which will readily enable the reader to make full use of all the advantages of the tables.

Translations of this valuable little work from the Dutch in to English, French, Italian, and German, may be obtained through Williams and Norgate, booksellers.

April, 1883.

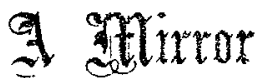

\section{OF THE PRACTICE OF}

\section{MEDICINE AND SURGERT IN THE}

\section{HOSPITALS OF LONDON.}

Nulla est alia pro certo noscendi via, nisi quam plurimas et morborum et issectionum historias, tam aliornm proprias, collectas habere et inter se com parare-Morgagri, De Sed, et Caus. Morb., lib. 1t. Procmium.

\section{ROYAL INFIR.MARY FOR CHILDREN.}

CLINICAL REMARKS ON CASES OF INFANTILE PARALYSIS,

(Under the care of Dr. WrLks.)

THE subject of infantile paralysis having of late been before the profession, the following short report of cases of this disease may be of some interest. Amongst ont-patients it is almost impossible to take a very full account of their histories, and much less possible is it to watch the cases to their terminations. The following short notes, however, all refer to a question which has been lately much discussed-whether there be any accompanying symptoms referable to a change in the cerebral or spinal centres. It will be seen that the cases corroborate the general professional experience, that although very often there is evidence of some general nervous derangement, yet that this is by no means always the case. It is for this reasonthe absence of all lesion-that the name essential paralysis has been given to it by the French. In the following cases, as in others, there is sufficient to suggest some central cause, yet this must not be assumed in those where no history was obtainable indicative of such disturbance. We think it must not be assumed, in the case of a child previously in good health in whom an arm or leg is found paralysed, that the child must have had a convulsion, followed by a general paralysis, and in whom both the attack and recovery were unknown to the mother, and only, indeed, suggested to the medical man by the remnant of paralysis which he finds. The subject is one of the most interesting in nervine pathology; but, considering that perfect recovery sometimes takes place, it is too much to assume that an organic lesion must always have occurred. A fatal result seldom takes place; and hitherto, we believe, no postmortem examination has been made to decide the point. It is scarcely necessary to allude to the absurd popular opinion of attributing every child's malady to the teeth, whether it be nervous, cutaneous, or gastric. That great changes occur in the body about the period of dentition every medical man knows, but that the direct process of tooth-cutting has arything to do with the disorder there is no proof, although we are ready to admit that much may be due to refex action.

It will be seen that in some of the following cases the child has gone to bed well and been taken up in the morning paralysed in the arm or leg. We have surmised whether in such cases the paralysis may not have been purely local, and due simply to pressure on the nerve of the limb, or possibly some. times to cold applied to the surface, in the same way as facial paralysis may arise from a coup de vent. We have thought this, because in many cases we have been unable to trace any cause whatever for the attack ; and we know, indeed, one in stance where a child in good health, having sat for a considerable period at a window with his leg donbled nnder him, had the limb quite benumbed and rendered helpless in consequence, so that he was obliged to be carried to bed by the nurse. On the following morving the leg was found still paralysed, preventing the child from standing. He gradually recovered by sea-bathing in the course of two or three weeks. If the occurrence bad not been observed by the nurse the cause would have recaained altogether unknown to the parents of the child. We see no reason, therefore, why the paralysis may not in some cases have no more deep.seated cause than accidental pressure. In others a blow may, we think, be the starting-point of the disease.

It has been said that this affection is connected with club. foot, and some have described them together; owing, however, to the divided practice of the pbysician and surgeon, perhaps neither the one nor the other is the tittest person to decide the question. But, for on: own part, we have never heen of opinion that the two diseases are pathologically associated. Talipes we have regarded as a result of spasm of the muscles, connected often with general convulsions, and arising from nervous irritation during either intra or extra uterine life; whereas in fantile paralysis, if not curer, does not, so far as our experience goes, terminate in sflasm, but in atrophy of the limb: the muscles waste, and the whole extremity becomes smaller or ceases to grow with the rest of the body; the consequence being that the limb hangs belplessly at the side, and in the case of the leg often obliging the patient to use a crutch, as the enfeebled limb does not reach the ground. Without examining the limb, the impression might be that such a patient had suf. fered from hip-joint disease in infancy. If a child with club. foot be brought to a surgeon, and a history of convulsions followed by a contraction of the leg be related, we should not regard this as a case of infantile paralysis; we believe the pathology of the two is different, and a different treatment is required.

A certain proportion of cases recover, althongh we cannot state what that number is, for reasons already given. We have never found any particular medicine which can be styled a remedy; but tonics, and all means which will stimulate the limb, are good-as rubbing it, exercising it as much as possible, and galvanism. The latter we have seen very serviceable; for if it acts in no more direct manner on the inert functions, it stimulates the muscles and prevents their waste. The only drawback to this remedy is the dread experienced by the child, which is sometimes so great that it cannot be persevered with. Of course, if there appear to be any special cause for the paralysis in the nervous centres, in the bowels or teeth, appropriate remedies will be given.

CASE 1.-Jane F- aged twenty months. Well up to six month a go, when she had convulsions, and very soon afterwards it was observed that the right arm was weak. There was now almost total paralysis of motion in this arm; child otherwise quite well. Occasional alterative powders of the soda-withmercury powder, embrocations, and galvanism, were prescribed. The child left at the end of a month, when the arm had made a decided improvement.

CASE 2. - Nelly S- aged seven months. A month ago the mother noticed that the child had quite lost the use of the right leg. Now it was found perfectly paralysed, and dangled about just as it was moved. The child was very well, and the mother said it had never had auy illness whatever, nor any trouble with the teeth. Ordered the same remedies as in the case above. Improvement slight. This child was seen a year afterwards, and the right leg was still weaker than the other.

CASE 3.-James $\mathbf{H}-$, aged a year and a half. Two weeks ago, when taken from his bed, the mother noticed that he could not stand on his right leg. Had no other symptoms; health good, and always had been so. Leg to be rubbed, and electricity used. Improving when he left.

CASE 4.-Henry B-, aged three years and a half. This child had been at the infirmary various times during the previous two years, and exemplified very well the consequences resulting from this affection if not cured. The left leg during this period had been partially paralysed; the limb was much smaller than the other, and so weak that the child could with difficulty bear his weight upon it. He could, however, just walk. As galvanism had never been used, it was ordered; but the patient was so alarmed by it that it was obliged to be discontinued. He was under notice for some weeks, but had not much improved.

CASE 5. - Sarah B-, aged a year and a half. The mother noticed that the child was unable to move her arm for the last few days. The child was in perfect healtb, and no local cause (as injury) could be discovered. She remained until the card had expired, when the arm bad slightly improved in strength, but not to any great degree. The child's health in other respects was excellent.

CASE 6.-Thomas $M$ - , aged two years and a half. Paralysed in the left leg; could move it slightly when in the 